\title{
Relações entre as razões de isótopo de oxigênio na neve e no gelo do Neva- do Illimani (Bolívia) com a variabilidade temporal da precipitação sobre a América do Sul
}

\author{
Éder Leandro Bayer MAIER ${ }^{1}$, Sandra BARREIRA² \& Jefferson Cardia SIMÕES ${ }^{1}$
}

(1) Centro Polar e Climático, Universidade Federal do Rio Grande do Sul. Av. Bento Gonçalves, 9.500, CEP 91.540-000, Porto Alegre, RS, Brasil.Email: edermaier@furg.br jefferson.simoes@ufrgs.br.

(2) Serviço Meteorológico da Armada Argentina. Av. Comodoro Py, 2055, Edifício Libertad, Piso 15, CPA 1104, Cidade Autônoma de Buenos Aires, Argentina. E-mail: barreira.sandra@gmail.com.

Recebido em 08/2015. Aceito para publicação em 04/2016. Versão online publicada em 31/05/2016 (www.pesquisasemgeociencias.ufrgs.br)

\begin{abstract}
Resumo - Este artigo examina as relações temporais entre a série de razão de isótopos estáveis de oxigênio $\left(\delta^{18} 0\right)$, obtida de um testemunho de gelo do Nevado Illimani, Bolívia $\left(16^{\circ} 37^{\prime} \mathrm{S}, 67^{\circ} 46^{\prime} \mathrm{W}\right)$, com séries da precipitação sobre a América do Sul. Utilizou-se dados de $\delta^{18} 0$ dos primeiros $50 \mathrm{~m}$ desse testemunho e os totais mensais de precipitação coletados em 890 estações meteorológicas sul-americanas no período entre 1979-2008. As amostras da precipitação foram dispostas em uma grade com resolução de $\sim 2^{\circ}$ de latitude e longitude, para o zoneamento espacial da variabilidade temporal, utilizando-se da Análise das Componentes Principais (ACP) no Modo-S. As relações entre o registro do $\delta^{18} \mathrm{O}$ com a ocorrência de secas e chuvas acima da média na América do Sul alteram-se sazonalmente em função da migração espacial dos mecanismos de transporte e convergência da umidade. A variabilidade temporal interanual da precipitação nas regiões equatorial e subtropical é a que possui maior semelhança com a variação do $\delta^{18} 0$ no Nevado Illimani. Essa relação é explicada pelo controle da temperatura superficial dos oceanos Pacífico Equatorial e Atlântico Norte sobre as anomalias de precipitação nas duas regiões e que ocorrem com frequências temporais entre $24 \mathrm{e}$ 60 meses. As séries do $\delta^{18} 0$ e da precipitação possuem ciclos temporais de alta frequência espectral que variam independentemente, porque esses ciclos são controlados por fatores locais.
\end{abstract}

Palavras-chaves: glaciais tropicais, reconstrução paleoclimática, ACP.

\begin{abstract}
Relations BEtWeEn the oxygen isotope RATios in the Nevado Illimani (Bolivia) SNOW AND ICE WITH THE PRECIPITATION TEMPORAL VARIABILITY OVER SOUTH AMERICA. This article examines the temporal relations between the oxygen stable isotopes ratio $\left(\delta^{18} 0\right)$ in an ice core from the Nevado Illimani, Bolivia $\left(16^{\circ} 37^{\prime} \mathrm{S}, 67^{\circ} 46^{\prime} \mathrm{W}\right)$, with precipitation series from South America. We used $\delta^{18} \mathrm{O}$ data from the upper $50 \mathrm{~m}$ of this core and precipitation monthly totals collected at 890 weather stations in South America in the period 1979-2008. Precipitation data were arranged in a grid with $\sim 2^{\circ}$ latitude and longitude resolution, for zoning the spatial temporal variability, using the Principal Components Analysis Mode-S. The relation between the $\delta^{18} 0$ record with drought and rain events above the South America mean values changes seasonally due to spatial migration of transport mechanisms and moisture convergence. The precipitation interannual temporal variability in the equatorial and subtropical regions is the one with the greatest similarity to $\delta^{18} 0$ variations in the Nevado Illimani. This relationship results from the control of precipitation anomalies in the two regions by the surface temperature of the equatorial Pacific and North Atlantic oceans, at temporal frequencies from 24 to 60 months. The $\delta^{18} 0$ and precipitation series have temporal cycles of high spectral frequency that vary independently, as those cycles are controlled by local factors. Keywords: tropical glaciers, paleoclimatic reconstruction, PCA.
\end{abstract}

\section{Introdução}

Testemunhos de gelo são importantes fontes de informações do clima pretérito e de relações com variáveis atmosféricas. Por exemplo, nas regiões polares é possível estimar indiretamente a temperatura atmosférica usando a razão de isóto- pos estáveis $\left(\mathrm{H}^{2} / \mathrm{H}^{1}\right.$ ou $\left.\mathrm{O}^{18} / \mathrm{O}^{16}\right)$ e na região tropical o registro do $\delta^{18} 0$ está relacionado ao ciclo hidrológico (Bales \& Wolff, 1995).

Na América do Sul, a extração do testemunho de gelo no Nevado Illimani, Bolívia $\left(16^{\circ} 37^{\prime} \mathrm{S}, 67^{\circ}\right.$ $46^{\prime} \mathrm{W}$, altitude de $6.350 \mathrm{~m}$ ) visou obter informações pretéritas da dinâmica atmosférica atuante 
sobre o Planalto Sul-americano. Essa geleira é formada por acumulação de neve precipitada desde o Último Máximo Glacial, porém são os registros do último século que possuem melhor resolução temporal e confiabilidade (Ramirez et al., 2003).

Este artigo investiga as relações temporais entre a série de $\delta^{18} 0$ mensurado no testemunho do Nevado Illimani e as séries da precipitação observadas na América do Sul, a fim de verificar se é possível reconstruir a variabilidade da precipitação pretérita usando o $\delta^{18} 0$. Adicionalmente, foram investigados os fatores controladores dessas duas variáveis ao longo do tempo.

A investigação segue uma metodologia proposta por Compagnucci \& Richman (2007), que usa o método estatístico de Análise das Componentes Principais (ACP) no Modo-S para agrupar as amostras da precipitação e possibilitar a comparação das duas variáveis. Esse método é uma ferramenta eficiente na redução do volume de amostras a ser processada, porque identifica as zonas espaciais em que a variabilidade temporal da precipitação possui índice de correlação elevado e possibilita a identificação de uma série temporal para cada zona identificada.

A comparação entre as duas variáveis testa a existência de alguns pré-requisitos fundamentais para uma reconstrução paleoclimática confiável (Lorenz, 1964). Nesse contexto, as primeiras análises buscam identificar as relações temporais entre as variáveis e, posteriormente, analisar os fatores que controlam mutuamente a variabilidade das duas variáveis. Além disso, foi identificado os principais ciclos temporais das series, a fim de verificar as semelhanças das frequências em que ocorrem as principais variações das séries ao longo do tempo.

\subsection{Sobre o $\delta^{18} \mathrm{O}$}

A reciclagem da água diminui a proporção de isótopos mais pesados $\left(\mathrm{O}^{18}\right)$ que compõem a água precipitada em latitudes tropicais. Consequentemente, os valores do $\delta^{18} 0$ próximos de zero indicam que a umidade se originou da evaporação nos oceanos, já os valores mais negativos estão associados às massas de água sujeitas ao processo de evaporação-precipitação da umidade sobre o continente (Craig, 1961; Dansgaard, 1964).

No processo de evaporação-precipitação as diferentes pressões de vapor, que se refere à volatilidade dos elementos químicos, ocorrem os fracionamentos isotópicos, sendo que os isótopos de maior massa atômica $\left(\mathrm{O}^{18}\right)$ tendem a precipitar mais rápido do que aqueles de menor massa atô- mica $\left(0^{16}\right)$. Segundo Dansgaard (1964) cada ciclo completo desse processo reduz em aproximadamente $3 \%$ o $\delta^{18} 0$ como, por exemplo, um registro do $\delta^{18} \mathrm{O}$ de $-15 \%$ (média do registro do $\delta^{18} \mathrm{O}$ no Nevado Illimani - Fig. 1A) indica a ocorrência de cinco processos de evaporação-precipitação da água nas trajetórias entre o Oceano Atlântico e a geleira (Eltahir \& Bras, 1994).

Os seguintes fatores destacam-se no controle do fracionamento isotópico do $\mathrm{O}^{18}$ no Nevado Illimani: i) Continentalidade - a distância de $3.000 \mathrm{~km}$ entre o nevado e o Oceano Atlântico é o principal fator que condiciona a média da razão isotópica entorno de 15\% (Eltahir \& Bras, 1994); ii) Altitude - a diminuição da temperatura e da disponibilidade de água na atmosfera aumenta o fracionamento isotópico do $\mathrm{O}^{18}$ (Vimeux et al., 2005); iii) Sazonalidade - no verão, a entrada de água evaporada do oceano Atlântico pela atuação dos ventos monçônicos e a elevação da temperatura atmosférica no interior continental favorecem o transporte de isótopos com maior massa atômica para essa área; já no inverno, a interrupção dos ventos monçônicos e a diminuição da temperatura favorecem a redução do $\delta^{18} 0$ no interior continental por causa da maior reciclagem da água (Salati et al., 1979); iv) Evapotranspiração - cerca de 50\% da água precipitada sobre a floresta Amazônica é originada da evaporação da umidade continental, onde a vegetação equatorial desempenha importante função na regulação hídrica entre a litosfera e a atmosfera (Salati et al., 1979); e v) Variação da temperatura superficial dos oceanos tropicais - os impactos no ciclo hidrológico causados por alterações na temperatura superficial dos oceanos Pacífico e Atlântico são predominantes na escala interanual e interdecenal, onde o fenômeno El Niño - Oscilação Sul (ENOS) é o principal fator (Ramirez et al., 2003; Vuille et al., 2003). A variabilidade do Atlântico Norte exerce controle na recarga hídrica no leste da região equatorial, consequentemente, influencia no fracionamento isotópico preservado no Nevado Illimani.

Maiores informações sobre os registros paleoclimáticos do Nevado Illimani podem ser obtidas em Ramirez et al. (2003) e das relações entre a $\delta^{18} 0$ com a distribuição espacial da precipitação em Maier et al. (2016).

\subsection{Sobre a precipitação na América do Sul}

0 volume precipitado acima ou abaixo da média climática pode gerar grande estresse hídrico no ecossistema terrestre, porque altera drasticamente o regime hídrico em escalas temporais he- 


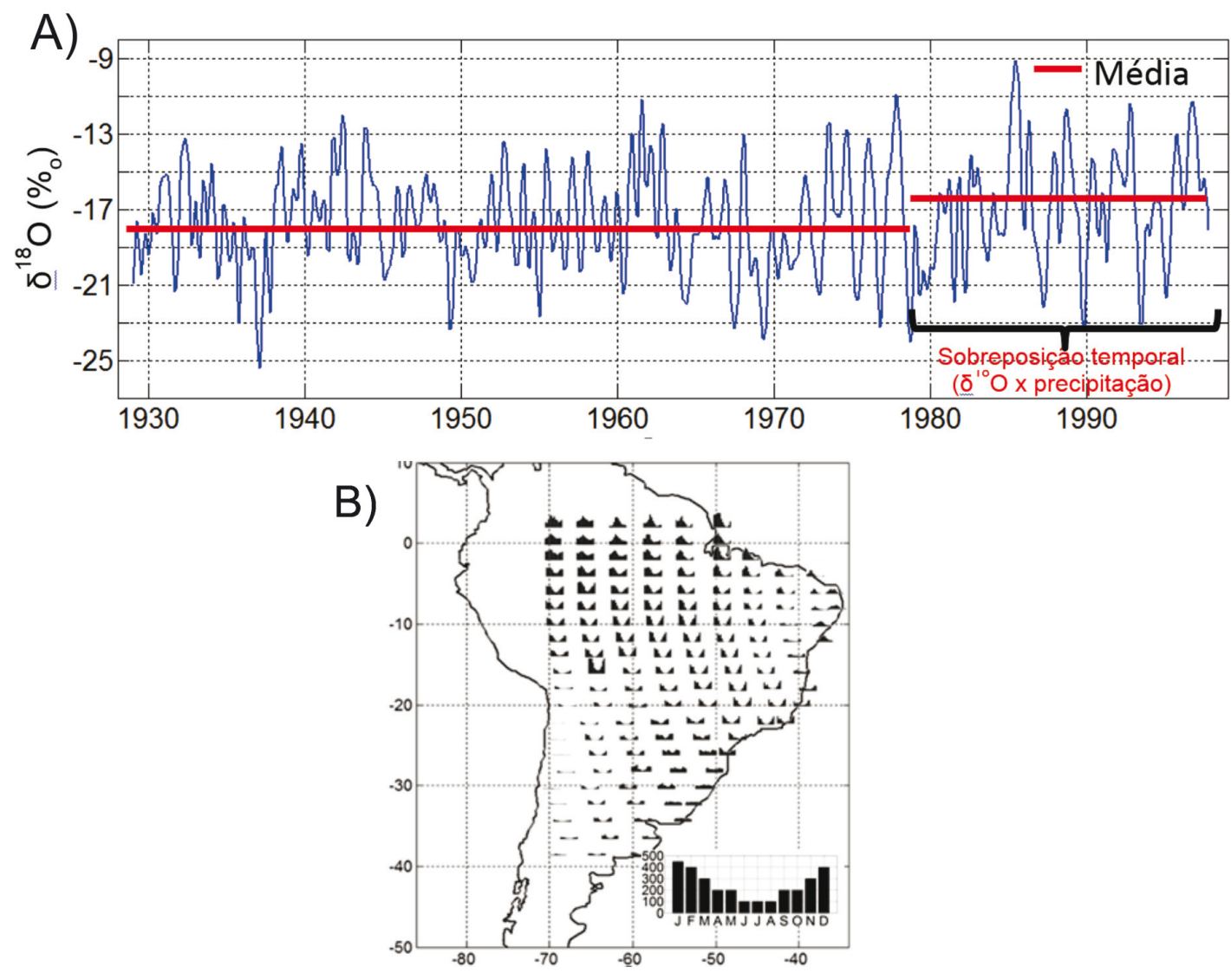

Figura 1. Série da razão isotópica do oxigênio dezoito $\left(\delta^{18} 0\right)$ obtido de testemunho de gelo do Nevado Illimani (Bolívia) com a identificação da média geral e do período de sobreposição temporal da amostragem das duas variáveis (A); e médias mensais da precipitação expressas por gráficos de barra com limiar de 500 milímetros no eixo vertical (B).

terogêneas. As alterações anômalas da precipitação decorrem de controles locais ou remotos nos mecanismos atmosféricos de transporte e convergência de umidade; no verão predominam os primeiros no controle da precipitação, e na primavera os últimos (Grimm, 2003).

Na América do Sul, as principais alterações anômalas da precipitação ocorrem em escala temporal intrasazonal, interanual e interdecenal (Grimm, 2009). Na escala intrasazonal, predomina a oscilação de Madden-Julian no controle das variações recorrentes em um período entre 40 e 50 dias. Essa oscilação é originada pela propagação de uma célula de circulação zonal de oeste para leste em latitudes equatoriais, e ela causa alterações de alta frequência temporal nos totais mensais da precipitação com a organização das convergências na região tropical pela passagem de centros ascendentes e descendentes da célula de circulação zonal (Madden \& Julian, 1994).

Já na escala interanual, são os impactos do ENOS e da variabilidade do oceano Atlântico Tropical que predominam no controle das anomalias da precipitação (Grimm, 2009). No caso de aquecimento do oceano Pacífico Equatorial (El Niño) constata-se o deslocamento da porção descenden- te da célula de Walker para o interior do continente, o que intensifica o deslocamento da umidade tropical em direção à região subtropical, consequentemente, há secas na região tropical e chuvas acima da média na região subtropical (Grimm, 2003). No caso do resfriamento do Pacífico (La Niña), observa-se aumento dos ventos zonais na região equatorial e bloqueios atmosféricos na região subtropical gerando chuvas acima da média e secas nas respectivas regiões, porém esses impactos ocorrem predominantemente na primavera (Grimm, 2004).

Os impactos do fenômeno ENOS podem apresentar grande diversidade espacial, pois esse fenômeno interage com os mecanismos atmosféricos sazonais e apresenta diferentes magnitudes. Adicionalmente, há zonas de transição como, por exemplo, o sudeste brasileiro que pode registrar secas (chuvas acima da média) ou atraso (adiantamento) no início da estação chuvosa com a ocorrência do El Niño (La Niña) (Grimm \& Ferraz, 1998a, 1998b).

A variação da temperatura superficial do Atlântico Tropical origina alterações na precipitação com frequência temporal entre a escala interanual e interdecenal (Hastenrath, 1984). A área 
mais afetada pela variabilidade do Atlântico Tropical é a margem leste da região equatorial, que abrange o nordeste brasileiro e a porção leste da Amazônia (Nobre \& Shukla, 1996).

Os impactos na precipitação ocorrem por alterações na intensidade dos ventos alísios de nordeste ou por modificações na posição da Zona de Convergência Intertropical. No primeiro caso, o aquecimento (resfriamento) do Atlântico Norte diminui (aumenta) a intensidade dos ventos alísios de nordeste, consequentemente, o transporte de umidade para o litoral diminui (aumenta) (Enfield, 1996). No segundo caso, o padrão espacial bipolar da variabilidade do Atlântico Tropical favorece a alteração do gradiente meridional da temperatura e de pressão atmosférica, o qual desloca anomalamente a posição da Zona de Convergência Intertropical, por exemplo, quando o Atlântico Norte aquece (resfria) o Atlântico Sul resfria (aquece) e a Zona de Convergência Intertropical desloca para norte (sul) (Nobre \& Shukla, 1996).

\section{2 Área, materiais e métodos}

Foram operacionalizadas duas análises, uma exploratória e outra investigatória. Na primeira, as séries temporais da precipitação foram agrupadas espacialmente pela Análise das Componentes Principais no Modo-S. Na segunda, as amostras das duas variáveis foram comparadas pela mensuração do índice de correlação entre as séries temporais (A); pela análise visual das variações temporais da precipitação com a série temporal do $\delta^{18} \mathrm{O}$ (B) e análise espectral das séries temporais (C).

Os dados do $\delta^{18} 0$ são oriundos do testemunho de gelo recuperado no Nevado Illimani (Bolívia, $16^{\circ} 37^{\prime} \mathrm{S}, 67^{\circ} 46^{\prime} \mathrm{W}$ e altitude de $6350 \mathrm{~m}$ ), o qual possui $136,7 \mathrm{~m}$ e é composto por precipitações desde o Último Máximo Glacial. Neste trabalho somente as amostras dos primeiros $50 \mathrm{~m}$ (referentes ao período 1929-1998) são utilizadas (Ramirez et al., 2003).

A extração do testemunho de gelo foi realizada por uma equipe franco-suíço no ano de 1999, a qual também acondicionou e transportou as amostras até o Laboratoire des Sciences du Climat et de l'Environnement (LSCE) na França. Nesse laboratório, o testemunho foi fragmentado em porções de $7 \mathrm{~cm}$ e analisado em um espectrômetro de massa que mensura o número relativo de moléculas de $0^{18}$ contidas na amostra, conforme a equação 1 .

$\delta^{18} \mathrm{O}=\frac{1000\left[\left(\mathrm{H}_{2} \mathrm{O}^{18} / \mathrm{H}_{2} O^{1 Ø}\right)\right] \text { amostra }}{\left(\mathrm{H}_{2} \mathrm{O}^{18} / \mathrm{H}_{2} \mathrm{O}^{1}\right) \mathrm{SMOWV}}$

Eq. 1 onde, SMOW (Standard Mean Ocean Water) é uma amostra arbitrária que contém porcentagem de isótopos estáveis semelhante a composição média do oceano (Craig, 1961).

\subsection{Precipitação}

Dados mensais de 30 anos (1979-2008) da precipitação observada em 890 estações meteorológicas (Fig. 2A) mantidas por várias instituições foram utilizados: Instituto Nacional de Meteorologia (Brasil), Agência Nacional das Águas (Brasil), Serviço Nacional de Meteorologia e Hidrografia (Bolívia), Serviço Nacional de Meteorologia (Argentina), Departamento de Serviços Meteorológicos (Paraguai) e Departamento Nacional de Meteorologia (Uruguai).

Quando não existiam observações, foram utilizados dados estimados por modelagem numérica (Reanálise), conforme descrito por Kistler et al. (2001) ou por tratamento estatístico de imagens de satélites (Climate Prediction Center - Merged Analysis of Precipitation - CMAP), de acordo com o método proposto por Huffman et al. (1997) ou pela compilação e interpolação de dados observados proposto por Matsuura \& Willmott (2009) (University of Delaware), admitindo confiabilidade superior a $95 \%$.

Segundo Compagnucci \& Richman (2007), a heterogeneidade espacial das observações é uma limitação para a ACP, porque maximiza a importância da variabilidade temporal nas áreas onde há maior número de estações meteorológicas. Por isso, se manipulou as observações para construir uma grade equiespaçada (Fig. 2B), onde cada ponto da grade está centrado em uma área de 12.321 $\mathrm{km}^{2}$, independente da latitude em que o ponto se encontra. A série temporal de cada ponto foi obtida pela média das observações realizadas dentro do espaço que o ponto representa.

Maiores informações sobre o banco de dados de precipitação e sua análise pela ACP no Modo-S podem obtidas em Maier et al. (2016).

\subsection{Análise estatística}

Para maximizar as variações na precipitação causadas por fenômenos que não são sazonais, as médias climáticas foram subtraídas das amostras, originado as séries temporais de anomalias de precipitação.

A ACP no Modo-S foi utilizada para identificar as zonas espaciais em que as séries temporais anômalas da precipitação possuem variação parcialmente homogênea. Esse zoneamento foi operacio- 
A)

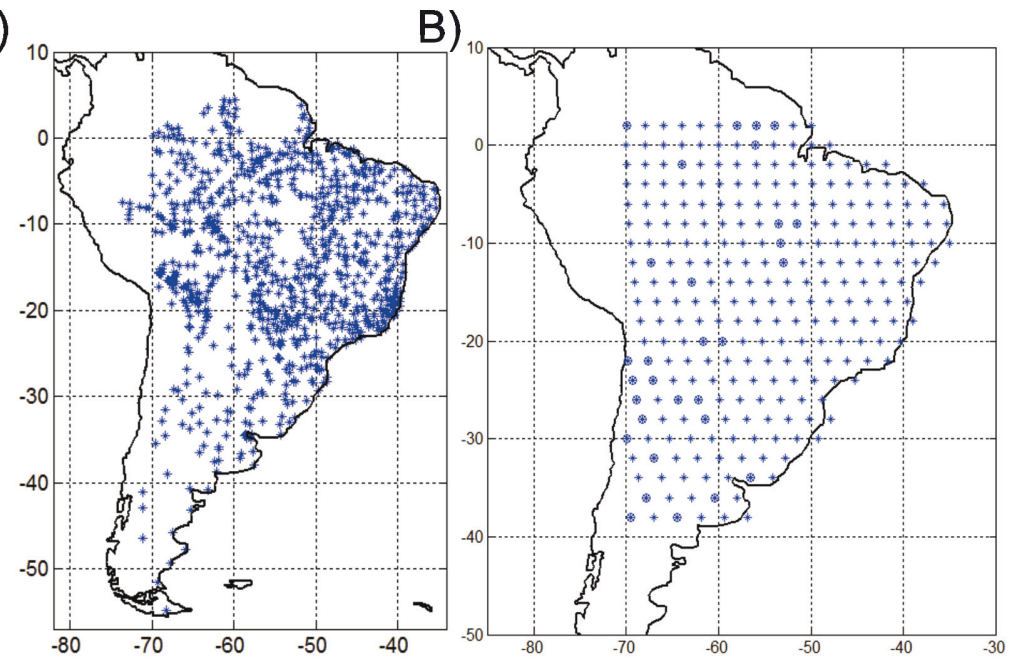

Figura 2. Distribuição espacial das estações meteorológicas argentinas, brasileiras, bolivianas, paraguaias e uruguaias (A) e grade equiespaçada (B) usada neste artigo.

nalizado em três fases: 1) mensuração da matriz de correlação, que contém o índice de correlação entre séries temporais anômalas; 2) estimativa das Componentes Principais (CP) por regressão linear para representar as distribuições temporais da precipitação que explicam as maiores porcentagens da variância; e 3) mensuração do Fator de Carga, que é o índice de correlação entre a componente principal e séries temporais anômalas da precipitação (Compagnucci \& Richman, 2007). Adotou-se como zona qualquer área que possui Fator de Carga superior a $|0,4|$.

Após o zoneamento, foi selecionada uma série temporal anômala no núcleo de cada zona para representar o comportamento médio da respectiva área. Essas séries foram utilizadas para análise visual, onde se compara a variabilidade da precipitação com a $\delta^{18} 0$ e para análise espectral, para identificar as principais frequências temporais de recorrência das anomalias da precipitação e da variabilidade da $\delta^{18} 0$.

\section{Resultados}

\section{1 Índice de correlação}

Os índices de correlação entre a série temporal de $\delta^{18} 0$ e as séries temporais anômalas da precipitação são próximos de zero quando se compara as amostras do período 1979 -1998. Porém, quando se fragmenta as séries de acordo com o ciclo sazonal e se compara amostras do verão, outono, inverno e da primavera, constatam-se índices superiores a $|0,5|$ e que uma mesma área pode possuir índices positivos e negativos. E essa alteração pode ser atribuída como a principal causa dos índices de correlação próximo de zero, visto que esse valor representa uma medida média (anual) das correlações positiva e negativas das distintas estações sazonais.

A configuração espacial dos índices de correlação (Fig. 3) evidencia que as relações entre as duas variáveis são parcialmente controladas pela sazonalidade da circulação atmosférica. Por exemplo, no verão austral as correlações positivas entre a razão do $\delta^{18} 0$ e a precipitação são observadas ao longo da Cordilheira dos Andes e correlações negativas sobre o Planalto Sul-americano em latitudes tropicais (Fig. 3A). Essa configuração espacial pode ter sua origem na entrada de umidade pelo hemisfério norte, nas proximidades do Amapá, e a sequência do transporte que ocorre ao longo da Cordilheira dos Andes (Zhou \& Lau, 1998). Portanto, a intensificação (desintensificação) dessa circulação atmosférica origina simultaneamente razões do $\delta^{18} 0$ maiores (menores) e chuvas acima (abaixo) da média mensal no oeste da Bacia Amazônica e chuvas abaixo (acima) da média mensal sobre o Planalto Sul-americano em latitudes tropicais.

No outono, as correlações positivas são observadas sobre o nordeste brasileiro e na área central do continente em latitudes extratropicais, e as correlações negativas situam-se na porção oeste da região equatorial (Fig. 3B). A possível ligação entre as variáveis pode ser explicada pela circulação atmosférica que transporta a umidade, a qual está atuando predominantemente no hemisfério sul e pode interagir com diversos mecanismos de convergência no interior continental, desde a borda sul da Amazônia até as pradarias sul americanas (Shi et al., 2000). Por ser uma estação intermediária entre o verão e o inverno, as relações entre as duas variáveis são intrínsecas ao final da estação chuvosa do regime monçônico, sendo que, nos anos em que as monções prolongam-se (diminuem) se observa simultaneamente aumento (di- 
minuição) do $\delta^{18} \mathrm{O}$ e das precipitações no nordeste brasileiro e na região extratropical.

No inverno há dois núcleos espaciais dos índices de correlações (Fig. 3C), um positivo nas regiões em que chove (nordeste brasileiro e região equatorial do hemisfério norte) e um negativo onde registra-se seca natural do regime monçônico (Fig. 1B). Na área monçônica, as correlações negativas indicam que é a reciclagem (não reciclagem) da água continental que gera as anomalias positivas (negativas) da precipitação e o maior (menor) fracionamento isotópico. Essa bipolaridade espacial das correlações ocorre porque nesta estação há uma interrupção natural das monções e um fortalecimento dos ventos do Anticiclone Semifixo do Atlântico Sul. Esse centro de alta pressão gera ventos que transportam pouca umidade para o interior do continente, em uma vasta área, entre as médias e baixas latitudes, desde o Atlântico Sul até a borda leste dos Andes Centrais (Zhou \& Lau, 1998).

$\mathrm{Na}$ primavera, constatam-se faixas zonais dos índices de correlação na região equatorial e tropical, respectivamente, negativos e positivos (Fig. 3D). Essa configuração espacial é originada pela variabilidade meridional das zonas de convergências, as quais são influenciadas pela variação da temperatura superficial do Oceano Pacífico e Atlântico. 0 aquecimento (resfriamento) das águas equatoriais no hemisfério norte desloca anomalamente a Zona de Convergência Intertropical para norte (sul) (Nobre \& Shukla, 1996). Adicionalmente, em resposta ao aquecimento (resfriamento) equatorial, a região extratropical resfria (aquece), o que intensifica (desintensifica) os ventos originados pelos anticiclones semifixos. Por consequ-
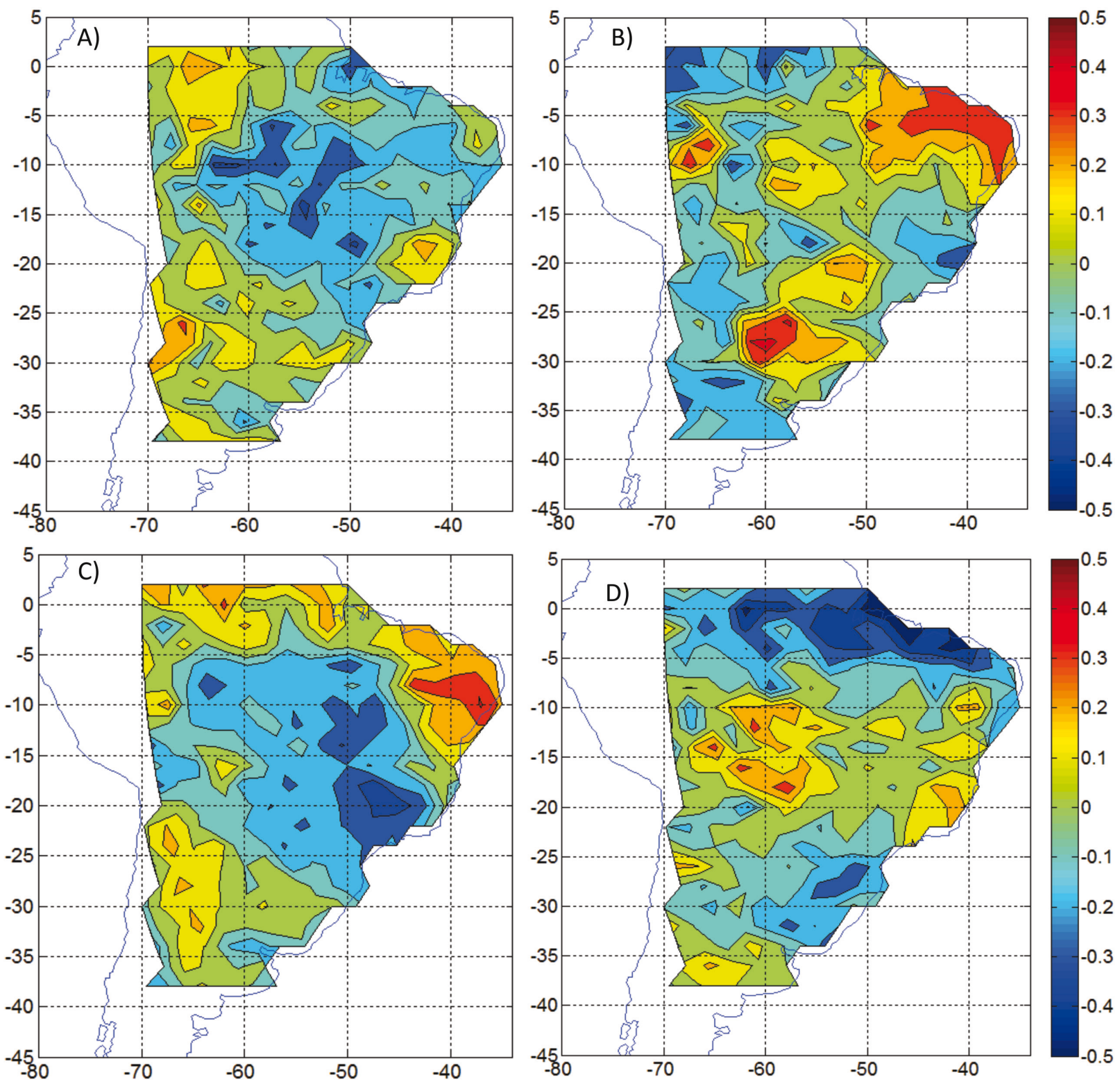

Figura 3. Índices de correlação entre o $\delta^{18} 0$ e as anomalias da precipitação no verão (A), outono (B), inverno (C) e outono (D) no período 1979-1998. 
ência, aumenta (diminui) o transporte de umidade para o interior do continente entre $10^{\circ} \mathrm{S}$ e $25^{\circ} \mathrm{S}$. Neste cenário também ocorre aumento (diminuição) das passagens dos sistemas frontais na região sul do Brasil e no Uruguai (Grimm et al., 2000).

\subsection{Fatores que controlam as variáveis}

As análises da variação temporal da precipitação, da localização geográfica de cada zona do Modo-S, da frequência espectral predominante, das correlações entre a precipitação e da pressão atmosférica, temperatura atmosférica em $2 \mathrm{~m}$ de altura e cobertura de nuvens (não mostrado) subsidiaram a identificação dos principais fatores que controlam a variabilidade temporal da precipitação (Quadro 1).

O fenômeno ENOS é predominante no controle da variabilidade temporal, na escala interanual e interdecenal, da precipitação sobre o continente sul-americano (Grimm, 2003, 2004). Além disso, a variabilidade do Atlântico Tropical influencia nas precipitações sobre a margem leste do continente em baixas latitudes e pode estar associada ao fenômeno ENOS, maximizando ou minimizando os impactos quando as anomalias da temperatura superficial dos oceanos no mesmo hemisfério possuem sinal igual/diferente (Nobre \& Shukla, 1996).

Fatores locais, quando comparado a fatores remotos, exercem controle na precipitação com elevada frequência temporal. Além disso, os fatores locais são mais importantes durante o verão e os remotos na primavera. No verão, a interação superfície-atmosfera é mais eficiente no controle do transporte e convergência da umidade do que as alterações dos mecanismos atmosféricos de mesoescala causadas pelos fatores remotos (Grimm, 2009).

Quadro 1. Principais características das séries anômalas da precipitação nas oito zonas do Modo-S, frequências (em meses) com alta potência espectral e indicação dos Fatores Controladores da variabilidade das séries temporais (F. Controlador - Fator Controlador, ENOS - El Niño Oscilação Sul e VAT - Variabilidade do Atlântico Tropical).

\begin{tabular}{|c|c|c|c|c|}
\hline \multirow{5}{*}{$\begin{array}{l}\text { J్ } \\
\text { J్ } \\
\text { N }\end{array}$} & 1 & $\begin{array}{c}\text { Anomalias podem equivaler a } 200 \% \text { da média } \\
\text { mensal }\end{array}$ & 60 meses & ENOS (forte) e VAT \\
\hline & 2 & $\begin{array}{l}\text { Longos períodos com anomalias positivas ou } \\
\text { negativas }\end{array}$ & 60 e 24 meses & ENOS (forte) e VAT \\
\hline & 4 & $\begin{array}{c}\text { Adiantamento ou atraso no início da estação chuvosa } \\
\text { ou verões secos/chuvosos }\end{array}$ & $\begin{array}{l}\text { Não há } \\
\text { predominância }\end{array}$ & ENOS (fraca) \\
\hline & 5 & $\begin{array}{l}\text { Anomalias de pequena magnitude quando } \\
\text { comparados a média mensal }\end{array}$ & 6 meses & $\begin{array}{l}\text { ENOS (fraca) e fatores } \\
\text { locais }\end{array}$ \\
\hline & 8 & $\begin{array}{c}\text { Anomalias de pequena magnitude que podem } \\
\text { equivaler } 200 \% \text { da média mensal }\end{array}$ & $\begin{array}{l}\text { Não há } \\
\text { predominância }\end{array}$ & Fatores locais \\
\hline \multicolumn{2}{|c|}{$\delta^{18} \mathrm{O}$} & $\begin{array}{l}\text { Períodos com grande ou pequena amplitude de } \\
\text { variação }\end{array}$ & 60,24 e 18 meses & $\begin{array}{l}\text { ENOS, VAT e fatores } \\
\text { locais }\end{array}$ \\
\hline
\end{tabular}

Em se tratando da razão do $\delta^{18} \mathrm{O}$, a variação temporal predominante ocorre na escala interanual influenciada pelo fenômeno ENOS (Ramirez et al., 2003; Vuille et al., 2003) e pela variabilidade do Atlântico Norte. Quando os fatores remotos aumentam (diminuem) o transporte de água evaporada no oceano Atlântico para o interior continental, há diminuição (aumento) da reciclagem da água continental e consequentemente diminuição (aumento) do fracionamento isotópico.

$A$ variação do $\delta^{18} 0$ possui períodos com maior e menor amplitude de variação que se intercalam entre $\sim 5$ anos (60 meses). Por exemplo, no perí- odo entre 1979 e 1984 a amplitude de variação se restringe entre $-14 \%$ e $-22 \%$ e no período entre 1985 e 1990 a variação é entre -9\%o e -23\%o. Além disso, há ciclos temporais com frequências de 18 e 24 meses, os quais possuem significância superior a 95\%. Provavelmente esses ciclos são causados pelos impactos do fenômeno ENOS e pela variabilidade da temperatura superficial do Atlântico Tropical no transporte da água evaporada no Oceano Atlântico.

A variabilidade da precipitação em baixa frequência espectral (entre 24 e 60 meses) também está relacionada ao ENOS e à variabilidade do 
Oceano Atlântico Tropical, pois ambos fenômenos possuem amplo espectro temporal, que pode variar entre 3 e 6 anos no caso do primeiro (Trenberth, 1997) e entre 9 e 12 anos no caso do segundo (Nobre \& Shukla, 1996). Mesmo as frequências de 24 meses têm origem na variação do ENOS (Richey et al., 1989), porque alterações no regime hídrico podem apresentar frequências menores do que a ocorrência desse fenômeno, pois esse regime interage com outros fatores controladores que causam interferência no ciclo temporal predominante.

As altas frequências temporais ou a ausência de um espectro predominante podem ser forçadas por fatores locais, por mecanismos atmosféricos móveis, pela variabilidade sazonal (quando muito forte) ou pela interferência de vários fatores controladores. Por exemplo, alterações no desempenho dos fluxos turbulentos combinados com perturbações sinóticas podem causar bloqueios atmosféricos (Hanser \& Chen, 1982) e a ampliação dos anticiclones perturbam a migração espacial dos mecanismos atmosféricos associados (Nakamura \& Wallace, 1993). A interferência de vários fatores controladores pode minimizar a predominância espectral de um fator ou o fator predominante pode gerar distintos impactos na variável analisada, como é o caso dos impactos do ENOS na precipitação da região sudeste do Brasil, que pode alterar o volume precipitado na estação chuvosa ou antecipar/atrasar o início das chuvas.

Comparando as duas variáveis, sob o aspecto dos fatores controladores da variabilidade temporal e das frequências espectrais, é possível afirmar que as maiores semelhanças entre a precipitação e o $\delta^{18} 0$ ocorrem nas zonas $1,2,6$ e 7 , porque ambos são controlados diretamente pelo aquecimento ou resfriamento anômalo das águas superficiais oceânicas equatoriais. Além disso, a circulação atmosférica de monções é o principal mecanismo de distribuição da umidade que precipita nessas zonas, onde o deslocamento dos jatos de baixos níveis causa impactos opostos na precipitação da região equatorial e subtropical (Cavalcanti \& Ambrizzi, 2009).

\subsection{Estudo de caso}

Na zona 1, o índice de correlação entre o $\delta^{18} 0$ e a precipitação é positivo no outono e no inverno (Fig. 3), estações que registam a maior parte da precipitação sobre o nordeste brasileiro. As anomalias positivas (negativas) da precipitação ocorrem concomitantes ao registro de $\delta^{18} 0$ máximo (mínimo). Por exemplo, a seca de 1982, as chuvas excessivas de 1985 e 1986 e as secas de 1987 e 1993. Porém, também há períodos com secas e chuvas acima da média em que não houve registro de mínimo e máximo de $\delta^{18} \mathrm{O}$ (Fig. 4B). Na primavera, o índice de correlação entre as variáveis é negativo, consequentemente, as secas (chuvas acima da média) estão associadas aos máximos (mínimo) de $\delta^{18} 0$, sendo que a influência remota dos oceanos possui máxima eficiência no controle da precipitação (Grimm, 2003). Entretanto, no outono e inverno, as anomalias da precipitação no nordeste apresentam menor magnitude porque os mecanismos atmosféricos de transporte e convergência estão naturalmente inibidos.

Essa similaridade entre as variáveis evidencia o mútuo controle pelo ENOS, porém a frequência espectral dos impactos desse fenômeno é diferente. Na precipitação o ciclo predominante é de 60 meses e no $\delta^{18} 0$ é de 24 meses. Outra incongruência entre as amostras é que as chuvas no nordeste brasileiro sofrem influência direta da variabilidade do Atlântico Tropical, e o registro do $\delta^{18} \mathrm{O}$ influência indireta, porque o fracionamento isotópico depende da recarga hídrica e da reciclagem da umidade sobre o continente. Assim, se as amostras não registram a variação do ciclo hidrológico do mesmo lugar e na mesma escala temporal, as relações entre as variáveis tornam-se parciais.

Na zona 2, as secas (chuvas acima da média) durante o verão são concomitantes ao máximo (mínimo) fracionamento isotópico do $\mathrm{O}^{18}$ como, por exemplo, as secas de 1987 e 1995 (Fig. 4C). Essa relação está associada à desintensificação (intensificação) dos alísios de nordeste que entram no continente pela porção oeste da bacia Amazônica. Por outro lado, nas demais estações (e em alguns casos no verão) predominam as correlações negativas entre as variáveis, como é o caso das secas de 1982, 1985 e 1992 que ocorrem simultaneamente aos máximos de $\delta^{18} \mathrm{O}$ e as chuvas acima da média nos anos 1982, 1984 e 1999 com os mínimos de $\delta^{18} \mathrm{O}$.

Em se tratando da precipitação na Amazônia, os ciclos temporais são recorrentes em duas frequências, em 24 e 60 meses, evidenciando que são os fatores remotos que predominam no controle da precipitação. Nesse contexto, Fisch \& Marengo (1998) afirmam que são as variações da temperatura superficial do Oceano Pacifico e Atlântico que causam tais alterações temporais cíclicas na precipitação.

Apesar do predomínio dos fatores remotos, também existem outros fatores locais que controlam a precipitação, como a evapotranspiração. Segundo Salati et al. (1979), 50\% da precipitação é em média formada pela evaporação da água con- 
tinental (reciclagem). Assim, o registro de anomalias positivas (negativas) da precipitação pode estar associado ao menor (maior) fracionamento isotópico se o aumento da precipitação foi causado pela intensificação dos ventos transportadores da umidade evaporada no oceano (da reciclagem).

As zonas 3 e 4 são áreas de transição quanto ao impacto do fenômeno ENOS (Grimm \& Ferraz, 1998a, 1998b). O El Niño (La Niña) pode atrasar (adiantar) o período chuvoso ou causar secas (chuvas acima da média). Além disso, a sobreposição dos impactos de fenômenos remotos e locais pode anular a frequência espectral predominante. Essa diversidade de padrões temporais da precipitação gera as principais incongruências entre as duas variáveis, exceto no inverno, quando o aumento de precipitação intensifica a reciclem da água situada sobre o continente e, por consequência, gera valores mais negativos de $\delta^{18} 0$ (Fig. 4D e 4E).

A zona 5 é a área em que a precipitação apresenta o padrão temporal mais homogêneo, quando comparado com as demais zonas, e a fraca influência do ENOS predomina no controle das anomalias negativas e positivas. Se tratando das relações temporais entre as duas variáveis, predomina a correlação negativa no verão e no inverno, porque
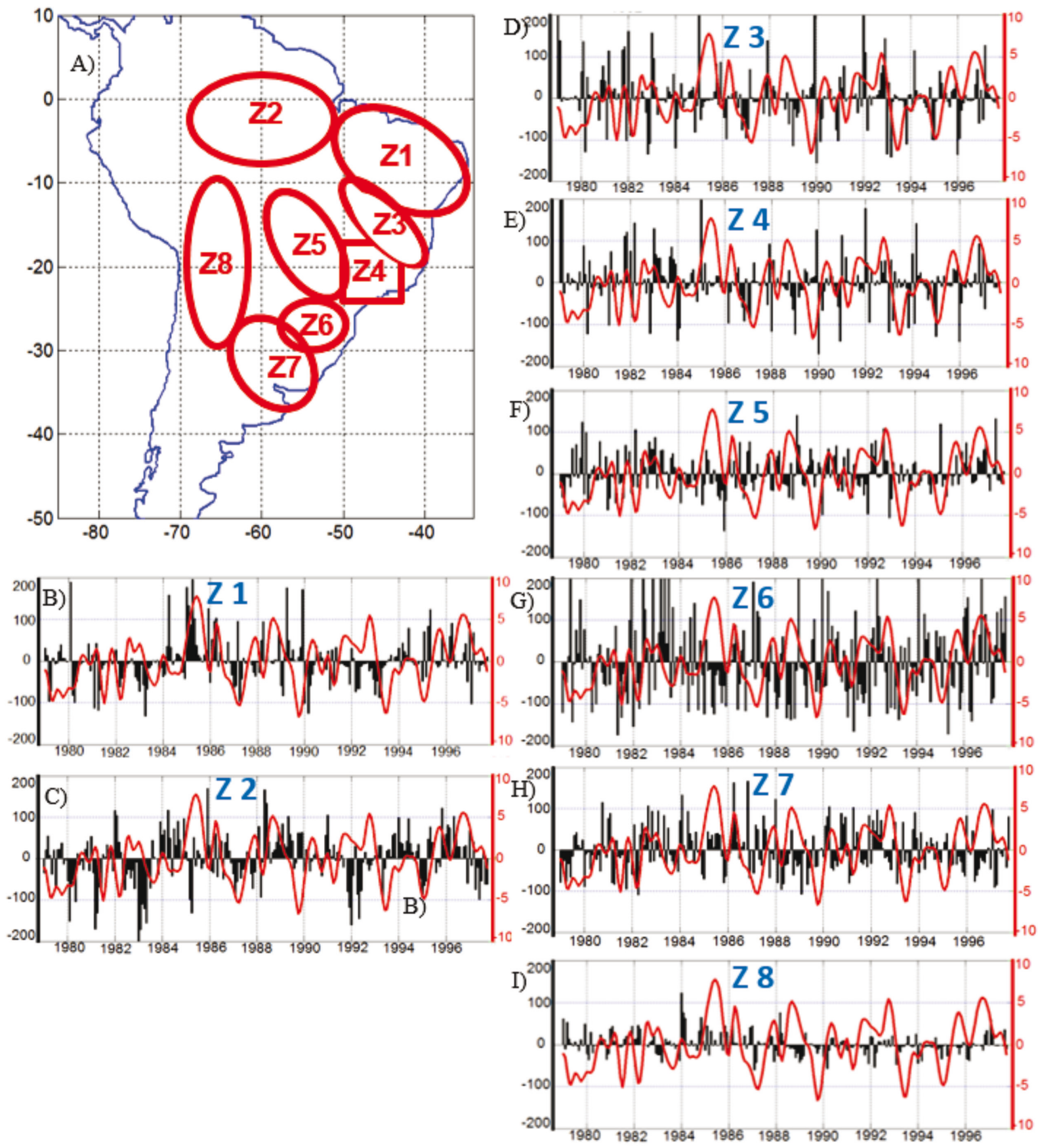

Figura 4. Zoneamento das séries anômalas da precipitação sobre a América do Sul (A), séries temporais que representam o comportamento médio das anomalias de precipitação em cada zona (B-I), barras pretas (com coordenadas na esquerda mensurada em milímetros) e de $\delta^{18} 0$ centrada em zero (curva vermelha e com coordenada na direita). 
o aumento (diminuição) da precipitação está relacionado ao aumento (diminuição) da reciclagem da água continental e o consequente aumento (diminuição) do fracionamento isotópico do $\mathrm{O}^{18}$ (Fig. $4 \mathrm{~F}$ ). Ao comparar as frequências dos ciclos temporais do $\delta^{18} 0$ e da precipitação na zona 5 , observa-se diferentes ciclos, sendo que o $\delta^{18} 0$ contém oscilações de baixa frequência e a precipitação de alta.

Nas zonas 6 e 7 as maiores anomalias da precipitação são causadas pelos impactos do fenômeno ENOS (Grimm et al., 2000) e ocorrem na frequência entre 50 e 60 meses. Porém, na zona 6, o ENOS é mais eficiente no controle da precipitação e causa anomalias com maior magnitude e por um período mais longo do que na zona 7. Sendo que, a porção mais ao sul da região subtropical (zona 7) registra alterações na precipitação somente nos eventos de El Niño ou La Niña fortes.

Essas áreas subtropicais possuem variabilidade temporal com um padrão espacial bipolar com a região equatorial, onde as alterações dos jatos de baixos níveis causam relação oposta entre as amostras de precipitação da região equatorial e subtropical (Cavalcanti \& Ambrizzi, 2009).

Na zona 6, as secas (chuvas acima da média) durante a primavera estão relacionadas a intensificação (desintensificação) dos ventos zonais em baixas latitudes, o que também influencia no transporte de isótopos de oxigênio mais (menos) pesados até o Nevado Illimani. No verão e no outono, o prolongamento (inibição) dos jatos de baixos níveis até as médias latitudes geram o aumento (redução) do $\delta^{18} \mathrm{O}$ e as anomalias positivas (negativas) da precipitação (Fig. 4G).

Na zona 7, as relações temporais entre a precipitação e o $\delta^{18} 0$ são similares às que ocorrem na zona 6 , porém na primeira elas não são válidas para o período do inverno austral, porque o controle da precipitação é realizado pelos sistemas frontais provenientes do extremo sul da América do Sul. Consequentemente, os fatores remotos de origem tropical perdem o controle da precipitação no inverno. Para exemplificar, a La Niña de 1985 exerceu controle predominante no verão e na primavera do respectivo ano, causando secas, mas no inverno os impactos desse evento foram interrompidos, gerando registros de chuvas acima da média. Cabe ressaltar que na zona 6 foram registradas secas durante as 4 estações.

Na zona 8, a variabilidade da precipitação é controlada principalmente por fatores locais, sendo que o ENOS gera fraca influencia na variação temporal. Esse predomínio dos fatores locais em relação aos remotos e a interferência entre eles pode explicar a variabilidade de alta frequência ou a falta da predominância espectral. Por se tratar de um regime climático parcialmente isolado aos do Planalto Sul-americano, as relações temporais entre as variáveis são tênues.

\section{Conclusões}

A distribuição espacial dos índices de correlação entre as séries temporais de $\delta^{18} 0$ e de precipitação evidenciaram que as relações entre essas variáveis se alteram sazonalmente.

No verão, a entrada de umidade na América do Sul é realizada pelos alísios de nordeste e pelos jatos de baixos níveis ao longo da Cordilheira dos Andes. Assim, quando essa circulação se intensifica (se desintensifica) ocorre o aumento (diminuição) das chuvas na porção oeste da bacia Amazônica, diminuição (aumento) da precipitação no centro oeste do Brasil e aumento (diminuição) do $\delta^{18} 0$.

No outono, a entrada de umidade para o interior do continente se restringe ao sul do Equador, portanto, quando essa circulação se intensifica (se desintensifica) ocorre o aumento (diminuição) das chuvas no nordeste, na borda sul da Amazônia e na porção leste da região extratropical, e assim ocorre a diminuição (aumento) da precipitação ao longo da Cordilheira dos Andes e aumento (diminuição) do $\delta^{18} 0$.

A circulação monçônica é naturalmente interrompida no inverno. Assim, a reciclagem da água continental torna-se mais importante para a formação das chuvas, exceto no nordeste brasileiro e no hemisfério norte. Quando há maiores (menores) precipitações sobre o Planalto Sul-americano também ocorre maior (menor) fracionamento isotópico do $\mathrm{O}^{18} \mathrm{da}$ água precipitada na geleira.

Na primavera, o aquecimento (resfriamento) dos oceanos Pacífico e/ou do Atlântico alteram os gradientes de pressão meridional, consequentemente, o deslocamento zonal para norte (sul) das zonas de convergências tropicais originam as secas (chuvas acima da média) na região equatorial, chuvas acima da média (secas) na faixa continental entre $10^{\circ} \mathrm{S}$ e $20^{\circ} \mathrm{S}$, secas (chuvas acima da média) na região extratropical e aumento (diminuição) do $\delta^{18} 0$.

Novos estudos poderiam explorar a possibilidade de estimar a precipitação pretérita a partir das variações de $\delta^{18} 0$. Para este novo objetivo, sugere-se que sejam utilizadas amostras da precipitação sobre o nordeste brasileiro (zona 1), a Amazônia (zona 2) e região extratropical (zona 6 e 7) porque a variabilidade temporal da precipitação nessas áreas apresentaram semelhanças com a variação do $\delta^{18} 0$. Por outro lado, existem incon- 
gruências entre as amostras e que podem comprometer a fidedignidade dos resultados, entre as quais, destacam-se: 1) a variabilidade temporal da precipitação é maior quando comparado com a variação de $\delta^{18} 0 ; 2$ ) os fatores locais e remotos que controlam a precipitação podem exercer influência em diferentes magnitudes; 3) as diferenças na frequências espectral dos ciclos temporal que ocorrem as anomalias; e 4) os impactos do fenômeno ENOS variam segundo a sua magnitude e a sazonalidade.

Agradecimentos - Ao Conselho Nacional de Desenvolvimento Científico e Tecnológico (CNPq) pelo financiamento de parte da pesquisa (Processo 557053/2009-9 - PROSUL) e os integrantes do Laboratoire des Sciences du Climat et de l'Environnement (França) que trabalharam na extração, preparação e análise do testemunho de gelo do Nevado Illimani. Éder Leandro Bayer Maier agradece à Coordenação de Aperfeiçoamento de Pessoal de Nível Superior (CAPES) pela concessão da bolsa DS e PDSE. Este artigo é uma contribuição do Instituto Nacional de Ciência e Tecnologia da Criosfera.

\section{Referências}

Bales, R.C. \& Wolff, E.W. 1995. Interpreting natural climate signals in ice cores. EOS, Transactions, American Geophysical Union, 76(47): 477-483.

Cavalcante, I.F.A. \& Ambrizzi, T. 2009. Teleconexões e suas influências no Brasil. In: Cavalcanti, I.F. (Ed.). Tempo e Clima no Brasil. São Paulo, Oficina de Textos, p. 353-374.

Compagnucci, R.H \& Richman, M.B. 2007. Can principal component analysis provide atmospheric circulation or teleconnection patterns? International Journal of Climatology, 28 (6): 703-726.

Craig, H. 1961. Isotopic Variations in Meteoric Waters. Science, New Series, 133(3465): 1702-1703.

Dansgaard, W. 1964. Stable isotopes in precipitation. Tellus, 16(4): 436-468.

Eltahir, E.A.B. \& Bras, R.L. 1994. Precipitation recycling in the Amazon basin. Quarterly Journal of the Royal Meteorological Society, 120(4): 861-880.

Enfield, D.B. 1996. Relationships of inter-American rainfall to Atlantic and Pacific SST variability. Geophysical Research Letters, 23(23): 3305-3308.

Fisch, G., Marengo, J.A. \& Nobre, C.A. 1998. Uma Revisão geral sobre o clima da Amazônia. Acta Amazônica, 28(2): 101-126.

Grimm, A.M. \& Ferraz, S.E.T. 1998a. Sudeste do Brasil: uma região de transição no impacto de eventos extremos da Oscilação Sul. Parte I: El Niño. In: CONGRESSO BRASILEIRO DE METEOROLOGIA, 10, 1998, Brasília, Distrito Federal. Anais ... Brasília, SBMet, v. 1, p. 1-5.

Grimm, A.M. \& Ferraz, S.E.T. 1998b. Sudeste do Brasil: uma região de transição no impacto de eventos ex- tremos da Oscilação Sul. Parte II: La Niña. In: CONGRESSO BRASILEIRO DE METEOROLOGIA, 10, 1998, Brasília, Distrito Federal. Anais ... Brasília, SBMet, v. 1, p. 1-5.

Grimm, A.M., Barros, V.R. \& Doyle, M.E. 2000. Climate variability in Southern South America associated with El Niño and La Niña events. Journal of Climate, 13(1): 35-58.

Grimm, A.M. 2003. The El Niño Impact on the Summer Monsoon in Brazil: Regional Processes versus Remote Influences. Journal of Climate, 16(C4): 263280.

Grimm, A.M. 2004. How do La Niña events disturb the summer monsoon system in Brazil? Climate Dynamics, 22(2): 123-138.

Grimm, A.M. 2009. Variabilidade interanual do clima no Brasil. In: Cavalcanti, I. F (Ed.). Tempo e Clima no Brasil. São Paulo: Oficina de Textos, p. 353-374.

Hanser, A.P. \& Chen, T.C. 1982. A spectral energetic study of atmospheric blocking. Monthy Weather Review, 110(9): 1146-1165.

Hastenrath, S. 1984. Interannual variability and annual cycle: mechanisms of circulation and climate in the tropical Atlantic. Monthy Weather Review, 112(6): 1097-1107.

Huffman, G.J., Adler, R.F., Arkin, P., Chang, A., Ferraro, R., Gruber, A., Janowiak, J., Mcnab, B., Rudolf, B. \& Schneider, U. 1997. The Global Precipitation Climatology Project (GPCP) combined data set. Bulletin of the American Meteorological Society, 78(1): 5-20.

Kistler, R., Kalnay, E., Collins, W., Saha, S., White, G., Woolen, J., Chelliah, M., Ebisuzaki, W., Kanamitsu, M., Kousky, V., Jenne, R. \& Fiorino, M. 2001. The NCEPNCAR 50-Year Reanalysis: Monthly Means CD-ROM and Documentation. Bulletin of the American Meteorological Society, 82(2): 247-267.

Lorenz, E.N. 1964. The problem of deducing the climate from the governing equations. Tellus, 169(1): 1-16.

Nakamura, H. \& Wallace, J.M. 1993. Synoptic behavior of baroclinic eddies during the blocking onset. Monthy Weather Review, 121(7): 1982-1903.

Nobre, P. \& Shukla, J. 1996. Variations of sea surface temperature, wind stress, and rainfall over the tropical Atlantic and South America. Journal of Climate, 9(10): 2464-2479.

Madden, R.A. \& Julian, P.R. 1994. Observations of the 40-50-Day Tropical Oscillation-A Review. Monthy Weather Review, 122(5): 814-837.

Maier, E.L.B., Barreira, S. \& Simões, J.C. 2016. Análise da relação entre o $\delta^{18} \mathrm{O}$ do Nevado Illimani com a distribuição espacial da precipitação sobre a América do Sul. Pesquisas em Geociências, 43(1): 5-16.

Matsuura, K. \& Willmott, C.J. 2009. Terrestrial Precipitation: 1900-2008 Gridded Monthly Time Series (versão 4.01). Newark - EUA: Center for Climatic Research, Department of Geography, University of Delaware, 2(1): 1-3. Disponível em: <http://climate. geog.udel.edu/ climate/>. Acesso em: 28 agosto de 2013.

Ramirez, E., Hoffmann, G., Taupin, J.D., Francou, B., Ribstein, P., Caillon, N., Ferron, F.A., Petit, J.R., Landais, 
A. \& Simões, J.C. 2003. A new Andean deep ice core from Illimani (6350 m), Bolivia. Earth and Planetary Science Letters, 212(3): 337-350.

Richey, J.E., Nobre, C. \& Deser, C. 1989. Amazon River discharge and climate variability: 1903 to 1985. Science, 246(4926): 101-103.

Salati, E., Dall'olio, A., Matsui, E. \& Gat, J.R. 1979. Recycling of water in the Amazon Basin: An isotopic study. Water Resources, 15(5): 1250-1257.

Shi, W., Higgins, R.W., Yarosh, E. \& Kousky, V.E. 2000. The Annual Cycle and Variability of Precipitation in Brazil. NCEP/Climate Prediction Center Atlas, 9(1): 1-25. Disponível em: <http://www.cpc.noaa.gov/ products/outreach/research_ papers/ncep_cpc_atlas/9>. Acesso em: 25 março de 2013.

Trenberth, K.E. 1997. The definition of El Niño. Bulle-

Man. 527

Editores: Ulisses F. Bremmer \& Paulo A. Souza. tin of the American Meteorological Society. 78(12): 2771-2777.

Vimeux, F., Gallaire, R., Bony, S., Hoffmann, G. \& Chiang, J.C.H. 2005. What are the climate controls on $\delta \mathrm{D}$ in precipitation in the Zongo Valley (Bolivia)? Implications for the Illimani ice core interpretation. Earth and Planetary Science Letters, 240(2): 205-220.

Vuille, M., Bradley, R., Werner, M., Healy, R. \& Keimig, F. 2003. Modelling $\delta^{18} \mathrm{O}$ in precipitation over the tropical Americas: 1. Interannual variability and climatic controls. Journal of Geophysical Research, 108(D6): 1984-2012.

Zhou, J. \& Lau, K.M. 1998. Does a Monsoon Climate Exist over South America? Journal of Climate, 11(5): 1020-1040. 